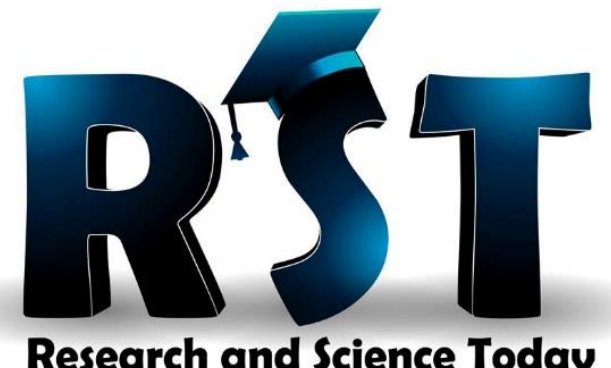

\title{
Research and Science Today
}

WWW.RSTJOURNAL.COM

\section{DOI:}

Title:

SHAKEN BABY SYNDROME, A CONCRETE PRESENCE

Section: MEDICAL SCIENCES

Issue: $\quad 1(19) / 2020$

Received: 16 December 2019

Revised: 25 January 2020

Accepted: 8 February 2020

Ramona-Mihaela NEDELCUŢĂ

Gigi CĂLIN

Mihai Cristian NEDELCUŢĂ

Oana IANA

Anca Roxana PASCAL

\begin{tabular}{l|c} 
Received: 16 December 2019 & Revised: 25 January 2020 \\
\hline Accepted: 8 February 2020 & Available Online: 15 March 2020
\end{tabular}

Paper available online HERE 


\author{
Ramona-Mihaela NEDELCUȚA $\breve{1}^{1}$ \\ Gigi CĂLIN ${ }^{2}$ \\ Mihai Cristian NEDELCUȚ $\breve{A}^{3}$ \\ Oana IANA ${ }^{4}$ \\ Anca Roxana PASCAL ${ }^{5}$
}

\begin{abstract}
:
A SHAKEN BABY IS A POSSIBLE MORE COMMON PEDIATRIC CONDITION THAN IS NORMALLY DIAGNOSED. IT IS NOT SO IMPORTANT TO ESTABLISH THE DIAGNOSIS, BECAUSE ONCE THE BRAIN DISORDERS ARE FORMED, THEY ARE IRREVERSIBLE, AS WELL AS HIGHLIGHTING POSSIBLE ALARM SIGNS THAT WOULD HELP PREVENT THE SYNDROME.

IN THIS SENSE, A SERIES OF QUESTIONNAIRES THAT COULD ASSESS THE FAMILY'S PREDISPOSITION TO APPLY SOME SUDDEN MOVEMENTS TO THE CHILD, WOULD PROVE TO BE LIFE SAVERS.
\end{abstract}

KEY WORDS: CHILD, SHAKEN, SYNDROME, BRAIN INJURY.

There have been several synonyms that describe the same entity as being practically a syndrome based on morphopathological changes following the shaken of a baby. It is also known as shaken, shaken or "shaken baby syndrome" (SBS).

It is not necessarily a recently diagnosed disease, the first descriptions dating back to 1970 when 2 doctors (a radiologist and a neurosurgeon) described a severe alteration of the brain, retina, ribs and limbs due to sudden movements exerted on or shaking their infants. The worldwide incidence is almost 10,000 cases, with mortality reaching $30 \%$. The predilection age is 6-12 months, not being totally excluded until the age of 5-6 years ${ }^{6}$.

The explanations of the appearance of the pathophysiological and morphopathological changes (examined in the deceased) are various:

\footnotetext{
${ }^{1}$ Department of Pediatrics, University of Medicine and Pharmacy of Craiova, Romania

${ }^{2}$ Department of Pediatrics, University of Medicine and Pharmacy of Craiova, Romania

${ }^{3}$ County Emergency Clinical Hospital from Craiova, Romania

${ }^{4}$ C.I. Parhon National Institute of Endocrinology Bucharest Romania Sectia este: Endemic goiter and its complications

5 Department of Anesthesiology and Intensive Care, University Emergency Hospital Bucharest, 169 Independentei Street, 050098, Bucharest, Romania

${ }^{6}$ Caffey, John (October 1974). "The Whiplash Shaken Infant Syndrome: Manual Shaking by the Extremities with Whiplash-Induced Intracranial and Intraocular Bleedings, Linked with Residual Permanent Brain Damage and Mental Retardation". Pediatrics. 54 (4): 396-403. PMID 4416579. Archived from the original on 2010-0313. Retrieved 2011-04-30; Lure Al. Shaken infant syndrome. Lancet 2001; 357 (9263): 1207
} 


\section{RST}

- the baby's brain is immature (as all organ systems), it can move in the same time with the movements of the skull, it can undergo rapid acceleration and deceleration when encountering a resistance (recoil effect), by hitting the inner walls of the cranial box.

- the total head / length ratio in infants is $1 / 4$ (compared to $1 / 10$ in the big child) the neck musculature is insufficiently developed and may result in limitations of head movements during violence.

- In the same immature brain, the cerebral vessels, as well as the immature and the fragile ones, suffer easily ruptures, with the appearance of epidural or subdural hematomas that, by the strictly exercised mechanical effect, produce the compression of the brain tissue ${ }^{7}$.

The consequences of these changes of normal anatomical structure are: seizures, coma, loss of consciousness, cardiorespiratory arrest (by direct action on the brain centers). There may also be: bone fractures (ribs, upper limbs, usually, but also lower), retinal hemorrhages, loss of visual acuity. The shaken baby's syndrome is a form of abuse exerted on the baby and practitioners should be trained to recognize signs and symptoms such as: inability, drowsiness, irritability, vomiting, bruising, breathing difficulties (dyspnea sine materia) or abnormal respiratory rhythms (Küssmaul breathing), fractures of the ribs, limbs, paralysis, convulsions, retinal hemorrhages, blindness. If anamnestic is related to bad habits in the family (increased nervousness, other members' suddenness, noise intolerance, baby's sleep by swinging on his feet) the syndrome can be suspected relatively easily. Sometimes a child with a disability is seen by a doctor, and a diagnosis can be difficult to determine. If the changes in the structure and function of the child appear suddenly, the careful anamnestic investigation is required ${ }^{8}$. (Fig 1)

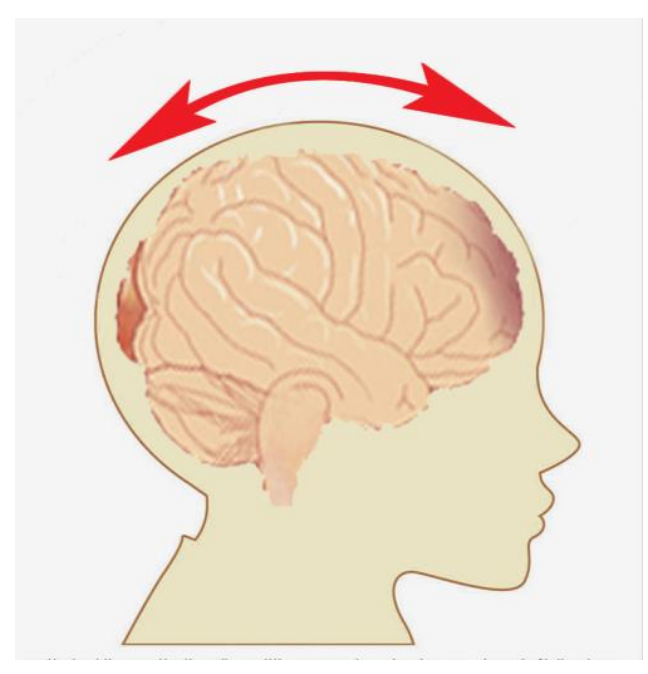

Fig 1 Shaken Baby Syndrome

\footnotetext{
${ }^{7}$ Stewart TC, Polgar D, Gilliland J, et al. Shaken baby syndrome and a triple-dose strategy for its prevention. J Trauma 2011;71(6):1801-1807

8 David TJ. Shaken baby (shaken impact) syndrome: non-accidental head injury in infancy. J R Soc Med 1999;92(11):556-561
} 
Complications are: seizures, paralysis, sight and hearing disorders (up to total loss), psychomotor retardation, behavioral disorders ${ }^{9}$.

The recognition of the syndrome requires compulsory hospitalization and emergency treatment through surgical techniques (stopping active cerebral hemorrhage), intubation and assisted ventilation. The magnitude of the changes made is determined by:

- X-ray (skull, spine, ribs, limbs)

- haematological examinations (eg post-hemorrhagic anemia)

- CT

- RMI

- ophthalmologic test

- audiometry

Not the treatment but the prevention of the syndrome will be defining for the evolution of the baby because a child who has survived the syndrome will no longer be normally developed but will have permanent sequelae ${ }^{10}$.

We recommend several measures for the family:

- hours of pre- and postnatal counseling, regarding the physiology of the baby, its handling, the necessary care

- parents should be informed about the syndrome

- the baby's crying should not be turned into a stress factor for the adults in the family, considering it to be a normal phenomenon.

- colic will have to be recognized and calmed correctly (position, massage, antialcoholic preparations, proper rhythm of meals)

- ventilation of the baby's room, outdoor walk, evening bath, quietly music, calms the child and relieves the anxieties of the surrounding adults.

- the mother does not have to neglect herself in order not to become nervous and frustrated.

- Tired or nervous adults should not be allowed to care for infants.

Starting from the description of the symptoms and the consequences of the syndrome, we tried to carry out questionnaires by interrogating for a period of 12 months all the parents of infants between 5-12 months to detect the possible risk that the respective child could ever suffer from SBS.

468 parents from all social backgrounds entered the study.

Regarding SBS, there are no noticeable differences between the environment of origin of the respective families. Moreover, it seems that the urban environment and the high socioeconomic level, together with the tendencies towards perfectionism of the parents, would increase the SBS risk.

The questions used are:

1. Is the child a stressor?

2. Has my mother experience postpartum mental changes?

\footnotetext{
${ }^{9}$ Al-Saadoon M, Elnour IB,GaneshA. Shaken baby syndromeas a formof abusive head trauma. Sultan Qaboos UnivMed J 2011;11(3):322-327

${ }^{10}$ Oehmichen M, Schleiss D, Pedal I, et al. Shaken baby syndrome: re-examination of diffuse axonal injury as cause of death. Acta Neuropathol 2008;116(3):317-329; Balci E, Gun I,Mutlu Sarli S, et al. Still an unknown topic: child abuse and "shaken baby syndrome". Ulus Travma Acil Cerrahi Derg 2011;17(5):430-434; Ettaro L, Berger RP, Songer T. Abusive head trauma in young children: characteristics and medical charges in a hospitalized population. Child Abuse Negl 2004;28(10):1099-1111
} 


\section{RST}

3. Is there alcohol in the family?

4. Is it a traditional family or another type of family structure?

5. What is the socio-cultural level of the parents?

6. Is the child permanently cared for by 1-2 people?

7. There are additional stressors (unemployment, divorce, family deaths, diseases of other family members)

8. Are parents informed about the baby's colic?

9. What measures of soothing do you use?

10. How does the baby sleep(swinging)?

A score above 5 on this questionnaire was associated with an increased risk of SBS onset.

Of the 468 infants studied, 254 were from urban areas and 214 were from rural areas.(Fig 2)

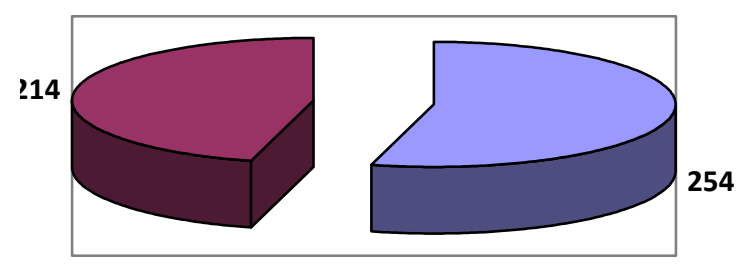

$\square$ urban $\square$ rural

Fig 2 Residential areas

The distribution by series was in favor of the boys and in the rural area, and in the urban:187 (urban area) - 73.6\% and 113 (rural area) - 52.8\%.(Fig 3)

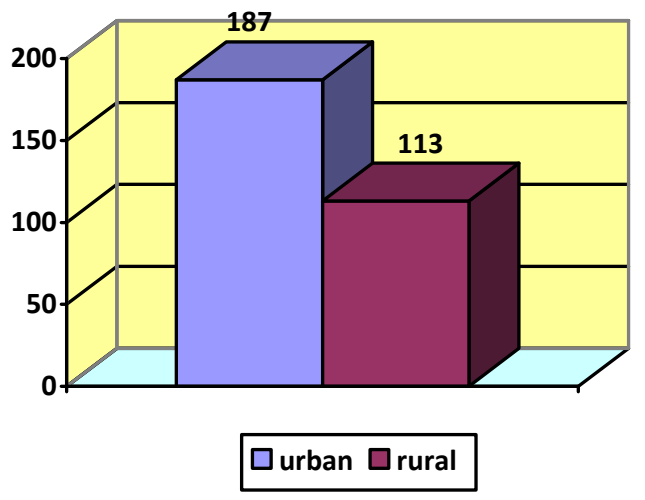

Fig 3 Boys distribution

Regarding the degree of education of the parents, they presented: higher education: 17 in rural and 93 in urban, high school 45 - in rural and 102 in urban, gymnasium 73 in rural 
and 41 in urban, primary classes 52 , rural and 11 urban the degree of illiteracy was 25 in the rural area and 7 in the urban area. (Fig 4)

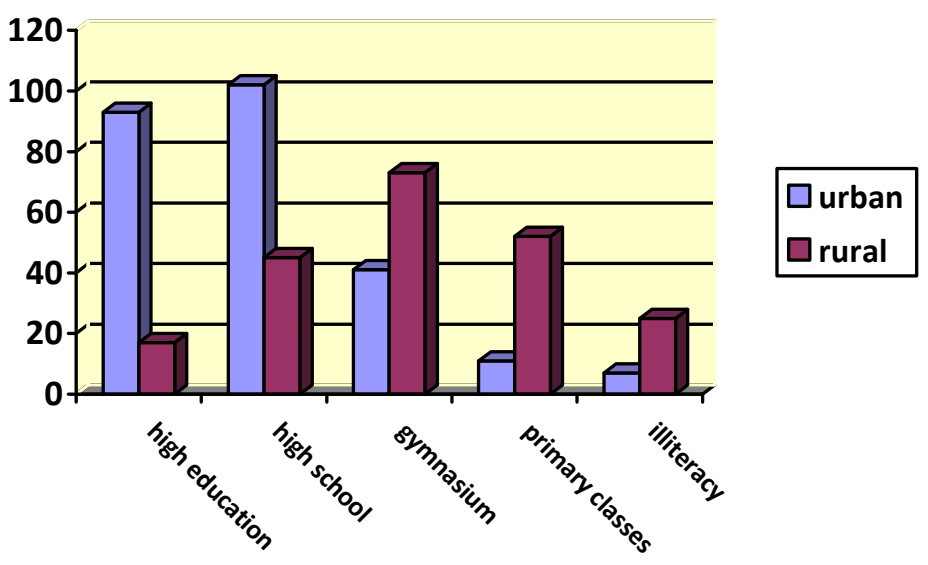

Fig 4 The degree of education of the parents

When applying questionnaires to parents' education groups, the results obtained were somewhat surprising.

The illiterate parents obtained predisposing data to SBS in 5 parents from rural (20\%) and 2 from urban $(28.5 \%)$.

In the group with higher studies, in 2 rural families (11.76\%) a possible tendency was observed for the aggression of the child and in about 18 families in the urban area $(19.3 \%)$ directly correlating with the stress and pressure level felt by parents.

For those with high school studies 5 out of 45 obtained a score of 6 in questionnaires $(11.11 \%)$ and 21 in urban areas $(20.58 \%)$. The almost double percentage in the urban environment was directly correlated with the social pressure felt, the frustration of the restriction of the activity with the appearance of the child, the service often in shifts of the second parent, the lack of communication and help, the big expenses, etc.

These things are not described or are of lesser importance in rural areas.

On the group with the graduated gymnasium, suggestive questionnaires were for 24 families from rural (32.8\%) and 18 from urban (43.9\%).

Lack of education, alcoholism, financial difficulties are better reflected in the city where the attractions are great, the ways to spend money are multiple, the comparisons work in the negative sense and the young families have no convenient help.

In the rural area, where the patriarchal society still thrives, with more families in the same area, even the same home, the degree of fatigue and frustration of the young parents is diluted, by the participation of other relatives in the child's upbringing.

In the case of those who graduated the primary classes, usually without jobs, and a precarious economic situation, the questionnaires were positive in 7 families from rural $(13.46 \%)$ and 1 from urban $(9.09 \%)$. In this case there are 2 interpretative possibilities: either the questions were not correctly understood and the answer is wrong, or, in large part, the children were neglected, deprived of the presence of the family, forgotten, so not physically traumatized at the age of infants, when it was realized the study. 


\section{RST}

\section{IN CONCLUSION:}

- SBS is a reality that we cannot deny, the possibility of occurrence in infants is significant.

- The environment and the education of the family can offer surprises: SBS seems to be correlated with the level of stress felt, rather than with the education, the educated families can escalate moments of anger, applied to the child.

- Information is very important due to the serious, irrecoverable consequences of SBS.

- The application of questionnaires showing the degree of risk for SBS could prevent the occurrence of consequences through the education of families, the using of psychological counseling and meetings, possibly doubled by the visualization of images with impact on the possible aggressors.

- There is the possibility of underdiagnosis of SBS in practice, often without making a clear parallelism between the possible sequelae (paralysis, blindness, deafness, psychomotor retardation) observed at an objective consultation of the baby and the existence of traumas which determine SBS.

\section{ACKNOWLEDGEMENTS}

All authors equally contributed in the research and drafting of this paper.

All authors report no potential conflict of interest. 


\section{SPRING 2020 \\ No. $1(19) / 2020$}

\section{REFERENCES}

1. Caffey, John (October 1974). "The Whiplash Shaken Infant Syndrome: Manual Shaking by the Extremities with Whiplash-Induced Intracranial and Intraocular Bleedings, Linked with Residual Permanent Brain Damage and Mental Retardation". Pediatrics. 54 (4): 396-403. PMID 4416579. Archived from the original on 2010-03-13. Retrieved 2011-04-30.

2. Lure Al. Shaken infant syndrome. Lancet 2001; 357 (9263): 1207

3. Stewart TC, Polgar D, Gilliland J, et al. Shaken baby syndrome and a triple-dose strategy for its prevention. J Trauma 2011;71(6):1801-1807.

4. David TJ. Shaken baby (shaken impact) syndrome: non-accidental head injury in infancy. J R Soc Med 1999;92(11):556-561.

5. Al-Saadoon M, Elnour IB,Ganesh A. Shaken baby syndromeas a formof abusive head trauma. Sultan Qaboos UnivMed J 2011;11(3):322-327.

6. Oehmichen M, Schleiss D, Pedal I, et al. Shaken baby syndrome: re-examination of diffuse axonal injury as cause of death. Acta Neuropathol 2008;116(3):317-329.

7. Balci E, Gun I,Mutlu Sarli S, et al. Still an unknown topic: child abuse and "shaken baby syndrome". Ulus Travma Acil Cerrahi Derg 2011;17(5):430-434.

8. Ettaro L, Berger RP, Songer T. Abusive head trauma in young children: characteristics and medical charges in a hospitalized population. Child Abuse Negl 2004;28(10):1099-1111. 